\title{
Proton Beam Stereotactic Radiosurgery for Pediatric Cerebral Arteriovenous Malformations
}

\author{
Brian P. Walcott, MD ${ }^{1,2}$, Jona A. Hattangadi-Gluth, MD $^{3}$, Christopher J. Stapleton, MD ${ }^{1}$, \\ Christopher S. Ogilvy, MD ${ }^{4}$, Paul H. Chapman, MD1, and Jay S. Loeffler, MD ${ }^{5}$ \\ ${ }^{1}$ Department of Neurosurgery, Massachusetts General Hospital and Harvard Medical School, \\ Boston, Massachusetts USA \\ ${ }^{2}$ Cardiovascular Research Center, Massachusetts General Hospital and Harvard Medical School, \\ Charlestown, Massachusetts USA \\ ${ }^{3}$ Department of Radiation Oncology, University of California San Diego, San Diego, California \\ USA \\ ${ }^{4}$ Department of Neurosurgery, Beth Israel Deaconess Medical Center and Harvard Medical \\ School, Boston, Massachusetts USA \\ ${ }^{5}$ Department of Radiation Oncology, Massachusetts General Hospital and Harvard Medical \\ School, Boston, Massachusetts USA
}

\section{Abstract \\ Background-For cerebral arteriovenous malformations (AVMs) determined to be high risk for surgery or endovascular embolization, stereotactic radiosurgery (SRS) is considered the mainstay of treatment.}

Objective-To determine the outcomes of pediatric patients with AVMs treated with proton SRS.

Methods-We reviewed the records of 44 consecutively treated pediatric patients (age < 18) who underwent proton SRS at our institution from 1998-2010. The median target volume was 4.5 \pm 5.9 $\mathrm{mL}$ (range $=0.3-29.0 \mathrm{~mL}$ ) and the median maximal diameter was $3.6 \pm 1.5 \mathrm{~cm}($ range $=1-6 \mathrm{~cm})$. Radiation was administered with a median prescription dose of $15.50 \pm 1.87$ CGE to the $90 \%$ isodose.

Results-At a median follow-up of $52 \pm 25$ months, two patients (4.5\%) had no response, 24 patients $(59.1 \%)$ had a partial response, and 18 patients $(40.9 \%)$ experienced obliteration of their AVM. The median time to obliteration was $49 \pm 26$ months, inclusive of 17 patients who underwent repeat proton radiosurgery. Four patients $(9 \%)$ experienced hemorrhage following treatment at a median time of $45 \pm 15$ months. Univariate analysis identified modified AVM scale score ( $\mathrm{p}=0.045)$, single fraction treatment $(0.04)$, larger prescription dose $(0.01)$, larger maximum dose $(<0.001)$, and larger minimum dose $(0.01)$ to be associated with AVM obliteration.

Corresponding Author: Brian P Walcott MD, Massachusetts General Hospital, 55 Fruit Street, White Building Room 502, Boston, MA 02114, Phone: 617726 2000, Fax: 617643 4113, walcott.brian@mgh.harvard.edu.

Disclosures: All authors have seen and approved this manuscript and have no disclosures to report. 
Conclusion-High-risk AVMs can be safely treated with proton radiosurgery in the pediatric population. Since protons deposit energy more selectively than photons, there is the potential benefit of protons to lower the probability of damage to healthy tissue in the developing brain.

\section{Keywords}

proton; radiosurgery; arteriovenous; stereotactic; AVM; Bragg peak; pediatric

\section{Introduction}

Arteriovenous malformations (AVMs) of the brain are vascular anomalies of children and adults that carry a high risk of hemorrhage, about 2-4\% per year over the patient's lifetime. ${ }^{1}$ The primary pathological phenotypic of AVMs is a direct communication between arteries and veins without an intervening capillary bed. Treatment of these lesions is limited to surgery, endovascular embolization, as well as focused, high dose radiation (stereotactic radiosurgery), especially in cases deemed too high risk for invasive intervention. No specific medical therapies currently exist. The annual risk of hemorrhage from AVMs is estimated at $2-4 \%$ based on their natural history. ${ }^{2-4}$ Therefore, the lifetime cumulative risk of this often devastating event is significant given a projected long life expectancy in children. ${ }^{3-6}$ For this reason, treatment of AVMs in children is typically recommended. For AVMs in areas of the brain deemed accessible, surgery is considered a definitive treatment that can result in lesion obliteration. ${ }^{7}$ Other techniques, such as endovascular embolization, occlude the arteriovenous shunting and can also result in lesion obliteration, with varying degrees of efficacy reported. ${ }^{8-13}$ Meanwhile, external beam radiation therapy, in the form of stereotactic radiosurgery, is generally reserved for lesions to be high risk for either operative and/or endovascular intervention. ${ }^{14}$

Several retrospective series of photon-based stereotactic radiosurgery in the pediatric population have been reported ${ }^{15-19}$, reporting obliteration rates ranging from following radiosurgery of 35 to $94 \%$. The long-term results of proton beam stereotactic radiosurgery (PSRS) in this specific age group are presented here for the first time. Proton beam radiation is unique from photon-based radiation in that when charged particles enter the body, they deposit little energy at the surface when their velocity is high. Rather, their ionizing radiation is released almost immediately before the particles come to rest, producing a steep drop-off in dose past the target. This phenomenon is known as the Bragg peak. ${ }^{20}$ This allows for extremely conformal dose distributions that minimize the exposure of normal brain tissue to radiation. ${ }^{21,22}$ Projected estimates of reduced radiation dose to adjacent neurocognitive and critical brain structures, as well as potential reduction in subsequent radiation-induced tumor risk with proton radiation, are important considerations in the pediatric population. ${ }^{23,24}$ Herein, we build on the experience generated at our institution from the first use of the proton beam for cerebral AVMs in $1965^{20}$ to report on a modern series of pediatric patients with AVMs treated with PSRS. 


\section{Methods}

\section{Patient selection}

Following IRB approval, we retrospectively reviewed 416 consecutive patients between 1998 and 2010 who underwent PSRS for arteriovenous malformations at our institution. All clinical, imaging, treatment dosimetry, and follow-up information were obtained from the electronic medical record. Patients were selected for inclusion if they were $<18$ years of age and had greater than six months of clinical and radiographic follow-up. PSRS was only offered as a treatment option to high-risk patients (based on lesion size or location) after comprehensive review and consensus agreement at a multidisciplinary neurovascular conference attended by neurosurgeons, radiation oncologists, and endovascular specialists.

\section{Treatment characteristics}

In a pre-treatment visit, three $1 / 16^{\text {th }}$-inch surgical-grade stainless steel fiducials were placed in the outer table of the skull under local anesthesia to facilitate precise treatment delivery. During treatment, patients were immobilized using skeletal pin cranial fixation or a modified relocatable Gill-Thomas-Cosman frame with dental fixation. ${ }^{25}$ A planning CT scan was performed with the patient in the treatment position and fused with MRI and/or CT angiogram to delineate the AVM nidus. To further ensure accuracy, a skull x-ray was obtained to ensure congruence between the radiosurgery target following each positioning using the previously implanted fiducials. PSRS was administered using energy-degraded $160-\mathrm{MeV}$ or $230-\mathrm{MeV}$ beams. Treatment was performed in a single fraction for nidus volume $<10 \mathrm{~mL}$, and two fractions (splitting the prescribed dose into two sessions) were considered for larger lesions or lesions in eloquent brain locations (brainstem, basal ganglia, sensorimotor cortex). For patients that received two fraction treatment, the dose was divided in half and administered in two sessions at a median period of seven days apart. Each beam was delivered, customized, and shaped by an individually designed brass aperture and range compensator via 3 or 4 ports. Plans were designed to limit dose to critical structures: brainstem $₫ 2$ GyRBE (Gray radiobiological equivalent ${ }^{26}$ ), optic chiasm $\$ 8 \mathrm{GyRBE}$, and optic nerve $\$ \&$ GyRBE, all while treating the entire nidus during each radiosurgery session. The prescription dose was planned to first, minimize radiation-related complications, and second, maximize the likelihood of AVM obliteration. ${ }^{27}$ The prescription volume was defined as the volume encompassed by the $90 \%$ isodose line. Homogeneity index was calculated as the maximum dose to the nidus divided by the prescription dose.

\section{Primary and secondary outcomes}

Follow-up was conducted at an initial six-month post-treatment visit, followed by at least yearly imaging and outpatient examinations. If patients were unable to travel to our institution for follow-up, physical exam documentation and imaging results were electronically uploaded into our medical record system for review. The primary outcome was defined as overall obliteration rate based on MRI or angiography. Treatment effect was defined as no response (no change in lesion size), partial response (decrease in lesion size), or total obliteration (absence of AVM nidus). Total obliteration was determined based on results of catheter-based angiography when possible (57\%), or, alternatively, MRI (43\%). On MRI scans, obliteration was defined as interpretation of disappearance of the AVM nidus on 
contrast-enhanced $\mathrm{T} 1$. With $\mathrm{T} 2$ weighted image sequences, the absence of any flow void signal in the previous region of nidus was interpreted as AVM obliteration. A consensus agreement was reached after review of the imaging by the treating neurosurgeon and radiation oncologist, and was further independently interpreted by a diagnostic radiologist. On catheter angiography, obliteration was defined as disappearance of any arteriovenous shunting (absence of flow in the region of the previously visualized nidus). All patients that did not achieve obliteration following initial treatment were offered re-treatment after a period of 4 years. The secondary outcome was hemorrhage rate following radiosurgery. Other complications were recorded and assessed. The outcomes (such as time interval to obliteration) were assessed based on the final result of all treatments received.

\section{Statistical Analysis}

Descriptive statistics were calculated for clinical and treatment factors, using the median as a measure of central tendency and the standard deviation as a measure of dispersion. A univariate analysis of clinical variables and total obliteration was performed. Comparisons of variables with non-normal distributions were made by the use of nonparametric statistics. Kaplan-Meier estimates of obliteration were performed for each of the four different groups according to modified AVM scale score distribution binning ( $₫ .00,1.01-1.50,1.51-2.00$, $>2.00)^{28,29}$ (Table 1). A log-rank Mantel-Cox test was used to determine the equality of total obliteration distributions. All statistical tests were two-sided, and $\mathrm{p}<0.05$ was predetermined to establish statistical significance. All analyses were performed using SPSS Statistics version 21 (IBM; Armonk, New York).

\section{Results}

We identified 44 patients under the age of 18 who received PSRS for cerebral AVMs after excluding five patients for insufficient clinical and radiographic follow-up ( $<6$ months) (Table 2). Brainstem and thalamus locations accounted for $50 \%$ of the treated lesions and over half of the lesions had modified AVM scale scores of $>1.00$. The median target volume was $4.5 \pm 5.9 \mathrm{~mL}$ (range $=0.3-29.0 \mathrm{~mL}$ ) and the median maximal diameter was $3.6 \pm 1.5 \mathrm{~cm}$ (range $=1-6 \mathrm{~cm})$ (Table 3$)$. At a median follow-up period of $52 \pm 25$ (range = 9-111) months, 2 patients $(4.5 \%)$ had no response, 24 patients $(59.1 \%)$ had a partial response, and 18 patients $(40.9 \%)$ experienced total obliteration of their AVM (Table 4). The median time to obliteration was $49 \pm 26$ months (range $=12-92$ ), inclusive of 17 patients who underwent a second proton radiosurgery (Table 5). This time represents the interval from the time of their first treatment. Four patients (9\%) experienced an AVM-related hemorrhage following their treatment at a median time of $45 \pm 15$ months (range $=30-66$ ). Additional morbidities included seizure, grade I headache, and development of a hemibody pain syndrome, each in a single patient. $86.4 \%$ of patients had no late complications from treatment. No patients died in this cohort. To our knowledge over the course of follow-up, no patient had developed a new intracranial lesion or tumor. Univariate analysis identified modified AVM scale score $(\mathrm{p}=0.045)$, single fraction treatment $(0.04)$, larger prescription dose $(0.01)$, larger maximum dose $(<0.001)$, and larger minimum dose $(0.003)$ to be associated with total AVM obliteration (Figures 1,2) (Table 6). Using the method of Kaplan Meier, estimates of total AVM obliteration were plotted for each of the four different groups according to modified 
AVM scale score distribution groups ( $₫ .00,1.01-1.50,1.51-2.00,>2.00$ ) (Figure 3). There was a significant difference in the test of equality for total obliteration distributions (Log Rank [Mantel-Cox] $\chi^{2}=8.26 ; \mathrm{p}=0.04$ ).

\section{Discussion}

One of the most devastating outcomes from cerebral AVMs is hemorrhage. The risk of this event is expressed in terms of a low annual risk of $2-4 \%$ per year $3,4,30,31$, although factors such as prior hemorrhage, age, location, and drainage patterns have been shown to influence their natural history. ${ }^{2,5,32}$ When considering treatment, the risk of morbidity and mortality associated with any intervention must be balanced against the natural history associated with hemorrhage. For the pediatric population in particular, one must anticipate the cumulative risk of hemorrhage over a presumably long lifetime. Similarly, one must also account for the long-term effects of treatments that are also relatively unique to the pediatric population, such as the development of radiation-induced tumors. ${ }^{33}$ In this report, we present a consecutive series of pediatric patients with high-risk cerebral AVMs treated with PSRS who experienced an overall modest rate of total obliteration (41\%) and a low rate of long-term complications (14\%). Many of the lesions in this series were giant AVMs, not typically considered suitable candidates for photon-based radiosurgery.

Within the radiosurgery literature, this study is the first report of exclusively pediatric AVMs treated with PSRS. Comparing these results to AVM obliteration rates reported in other radiosurgery series is challenging, as one has to account for the different modalities, lesion characteristics, and radiation dose administered, among other variables, in order to make meaningful interpretations. In general, our rate of obliteration falls within the previously reported range for total obliteration in children following radiosurgery of $35 \%$ to $94 \%{ }^{15-19}$, a range that encompasses a wide range of lesion characteristics and treatment indications. Perhaps more importantly, it is important to interpret obliteration rates in the context of their associated complication rates. It is well accepted that a relationship between AVM obliteration and radiation dose exists ${ }^{34,35}$, and is limited by the threshold of anticipated radiation-related complications. ${ }^{27}$ Treatment delivery in this series was always performed primarily with a goal of $<5 \%$ radiation-related complications and secondarily, to deliver the maximum conformal dose to the AVM nidus based on our institutional experience with the treatment of over 1329 patients with AVMs at the Harvard Cyclotron Laboratory (HCL) over three decades. ${ }^{27}$

Apart from possible radiation-related complications $(\mathrm{n}=2)$, the majority of the long-term complications in this series resulted from hemorrhage, arguably as a consequence of lesion persistence and/or the delayed nature of any treatment effect. Even while there is evidence that radiosurgery reduces the risk of hemorrhage in the period following treatment ${ }^{36}$, there is a significant interval of time before the risk approaches $0 \%$, even when a trajectory towards total obliteration is observed. This risk of hemorrhage is even more profound when a greater time interval to AVM obliteration exists, as was the case in 17 patients treated with repeated PSRS in this series. 
In order to predict outcomes prior to treatment, a modified radiosurgery-based AVM score was developed in LINAC and Gamma-Knife based series ${ }^{28}$, and has been subsequently validated in a PSRS series. ${ }^{37}$ In this report, we demonstrate that the scoring system can be of value in the pediatric population as well, where binning of scores results in distinct obliteration rates (inversely related to score). Further analysis of hemorrhage risk as it relates to modified radiosurgery-based AVM score was not possible secondary to our sample size and event occurrence $(n=4)$.

This series is unique from other radiosurgery series in that proton beam radiation was utilized, rather than x-rays. Among stereotactic radiation delivery modalities for AVMs, PSRS has an added advantage of allowing less collateral dose to surrounding brain tissue, which can lead to a more conformal dose distribution. This property is exploited when radical treatment plans are necessary, such as those where the AVM nidus occupies an irregular three-dimensional shape in close proximity to critical structures. ${ }^{38}$ The superior conformal dosimetry delivered by proton beam can potentially also limit radiation-related tumor risk, neurocogonitive effects, and other forms of radiation-induced injury in normal brain. ${ }^{39,40}$ Further study encompassing larger numbers of patients with extended follow-up is necessary to validate hypotheses such as these. The increase in proton treatment facilities, including those planned or under construction, may provide a treatment population size more appropriate for clinical trials. ${ }^{41,42}$ Additional considerations for future study also include an emphasis on cost-effectiveness.

\section{Limitations}

Inherent in this study is the potential for selection bias. While patients were evaluated in a multi-disciplinary clinic, the determination to pursue radiosurgery, as opposed to other treatment modalities or observation, was a clinical judgment that was not part of a rigid protocol. For example, the longstanding belief that all deep seated lesions are inoperable is a historical convention, and excellent outcomes have been reported from experienced centers. ${ }^{43}$ Additionally, patients recommended for observation were not accounted for in this study, although there is evidence that high grade lesions may actually have a lower hemorrhage risk than their lower grade counterparts. ${ }^{44}$ Long-term follow-up of these patients is essential, although difficult to track given the quaternary referral pattern at our center.

Measurement bias also exists, as the "gold-standard" diagnostic exam for AVM obliteration, a catheter-based cerebral angiogram, was only performed in $57 \%$ of patients. While it is most accurate to confirm obliteration of these lesions with cathether-based angiography, the radiation exposure, need for general anesthesia, and iatrogenic stroke risk are always considerations in the pediatric population. Even though MRI does not provide the diagnostic sensitivity or specificity of an angiogram with regards to AVM obliteration, it can provide unique information about the potential complications from radiosurgery, such as cerebra edema or radiation necrosis, none of which were seen in this series. 45,46 


\section{Conclusion}

High-risk AVMs can be safely treated with proton radiosurgery in the pediatric population.

Since protons deposit energy far more selectively than x-rays, there is the potential benefit of protons to lower the probability of damage to healthy tissue in the developing brain. The balance between dose, obliteration, and complications must be weighed carefully, mindful of the cumulative risk of hemorrhage over a patient's lifetime for persistent lesions.

\section{Acknowledgments}

Funding: JSL (NIH grant - 5P01CA021239-26)

\section{References}

1. Wedderburn CJ, van Beijnum J, Bhattacharya JJ, et al. Outcome after interventional or conservative management of unruptured brain arteriovenous malformations: a prospective, population-based cohort study. The Lancet Neurology. 2008; 7(3):223-230. [PubMed: 18243054]

2. Pollock BE, Flickinger JC, Lunsford LD, Bissonette DJ, Kondziolka D. Factors that predict the bleeding risk of cerebral arteriovenous malformations. Stroke. 1996; 27(1):1-6. [PubMed: 8553382]

3. Ondra SL, Troupp H, George ED, Schwab K. The natural history of symptomatic arteriovenous malformations of the brain: a 24-year follow-up assessment. Journal of neurosurgery. 1990; 73(3): 387-391. [PubMed: 2384776]

4. Brown RD Jr, Wiebers DO, Forbes G, et al. The natural history of unruptured intracranial arteriovenous malformations. Journal of neurosurgery. 1988; 68(3):352-357. [PubMed: 3343606]

5. Stapf C, Mast H, Sciacca R, et al. Predictors of hemorrhage in patients with untreated brain arteriovenous malformation. Neurology. 2006; 66(9):1350-1355. [PubMed: 16682666]

6. Forster DM, Steiner L, Håkanson S. Arteriovenous malformations of the brain: a long-term clinical study. Journal of neurosurgery. 1972; 37(5):562-570. [PubMed: 5076373]

7. Codd PJ, Mitha AP, Ogilvy CS. A recurrent cerebral arteriovenous malformation in an adult. 2008

8. Jayaraman M, Marcellus M, Hamilton S, et al. Neurologic complications of arteriovenous malformation embolization using liquid embolic agents. American Journal of Neuroradiology. 2008; 29(2):242-246. [PubMed: 17974613]

9. Ledezma CJ, Hoh BL, Carter BS, Pryor JC, Putman CM, Ogilvy CS. Complications of cerebral arteriovenous malformation embolization: multivariate analysis of predictive factors. Neurosurgery. 2006; 58(4):602-611. [PubMed: 16575323]

10. Wallace RC, Flom RA, Khayata MH, et al. The safety and effectiveness of brain arteriovenous malformation embolization using acrylic and particles: the experiences of a single institution. Neurosurgery. 1995; 37(4):606-618. [PubMed: 8559287]

11. Van Rooij W, Sluzewski M, Beute G. Brain AVM embolization with Onyx. American Journal of Neuroradiology. 2007; 28(1):172-177. [PubMed: 17213451]

12. Katsaridis V, Papagiannaki C, Aimar E. Curative embolization of cerebral arteriovenous malformations (AVMs) with Onyx in 101 patients. Neuroradiology. 2008; 50(7):589-597. [PubMed: 18408923]

13. Panagiotopoulos V, Gizewski E, Asgari S, Regel J, Forsting M, Wanke I. Embolization of intracranial arteriovenous malformations with ethylene-vinyl alcohol copolymer (Onyx). American Journal of Neuroradiology. 2009; 30(1):99-106. [PubMed: 18842759]

14. Barr JC, Ogilvy CS. Selection of treatment modalities or observation of arteriovenous malformations. Neurosurgery Clinics of North America. 2012; 23(1):63-75. [PubMed: 22107859]

15. Cohen-Gadol AA, Pollock BE. Radiosurgery for arteriovenous malformations in children. Journal of Neurosurgery: Pediatrics. 2006; 104(6):388-391. [PubMed: 16776373] 
16. Smyth MD, Sneed PK, Ciricillo SF, et al. Stereotactic radiosurgery for pediatric intracranial arteriovenous malformations: the University of California at San Francisco experience. Journal of neurosurgery. 2002; 97(1):48-55. [PubMed: 12134932]

17. Shin M, Kawamoto S, Kurita H, et al. Retrospective analysis of a 10-year experience of stereotactic radiosurgery for arteriovenous malformations in children and adolescents. Journal of neurosurgery. 2002; 97(4):779-784. [PubMed: 12405363]

18. Pan DH-C, Kuo Y-H, Guo W-Y, et al. Gamma Knife surgery for cerebral arteriovenous malformations in children: a 13-year experience. 2008

19. Dinca EB, de Lacy P, Yianni J, et al. Gamma Knife surgery for pediatric arteriovenous malformations: a 25-year retrospective study: Clinical article. Journal of Neurosurgery: Pediatrics. 2012; 10(5):445-450. [PubMed: 22938080]

20. Kjellberg RN, Hanamura T, Davis KR, Lyons SL, Adams RD. Bragg-peak proton-beam therapy for arteriovenous malformations of the brain. New England Journal of Medicine. 1983; 309(5):269274. [PubMed: 6306463]

21. Durante M, Loeffler JS. Charged particles in radiation oncology. Nature Reviews Clinical Oncology. 2009; 7(1):37-43.

22. Grün R, Friedrich T, Elsässer T, et al. Impact of enhancements in the local effect model (LEM) on the predicted RBE-weighted target dose distribution in carbon ion therapy. Physics in medicine and biology. 2012; 57(22):7261. [PubMed: 23075883]

23. Dennis ER, Bussiere MR, Niemierko A, et al. A Comparison of Critical Structure Dose and Toxicity Risks in Patients with Low Grade Gliomas Treated with IMRT versus Proton Radiation Therapy. Technology in cancer research \& treatment. 2012

24. Arvold ND, Niemierko A, Broussard GP, et al. Projected second tumor risk and dose to neurocognitive structures after proton versus photon radiotherapy for benign meningioma. International Journal of Radiation Oncology* Biology* Physics. 2012; 83(4):e495-e500.

25. Chen CC, Chapman P, Petit J, Loeffler J. Proton radiosurgery in neurosurgery. 2007

26. Paganetti H, Niemierko A, Ancukiewicz M, et al. Relative biological effectiveness (RBE) values for proton beam therapy. International Journal of Radiation Oncology* Biology* Physics. 2002; 53(2):407-421.

27. Barker FG, Butler WE, Lyons S, et al. Dose-volume prediction of radiation-related complications after proton beam radiosurgery for cerebral arteriovenous malformations. Journal of neurosurgery. 2003; 99(2):254-263. [PubMed: 12924697]

28. Wegner RE, Oysul K, Pollock BE, et al. A modified radiosurgery-based arteriovenous malformation grading scale and its correlation with outcomes. International Journal of Radiation Oncology* Biology* Physics. 2011; 79(4):1147-1150.

29. Pollock BE, Flickinger JC. Modification of the radiosurgery-based arteriovenous malformation grading system. Neurosurgery. 2008; 63(2):239-243. [PubMed: 18797353]

30. Mast H, Young WL, Koennecke H-C, et al. Risk of spontaneous haemorrhage after diagnosis of cerebral arteriovenous malformation. The Lancet. 1997; 350(9084):1065-1068.

31. da Costa L, Wallace MC, ter Brugge KG, O'Kelly C, Willinsky RA, Tymianski M. The natural history and predictive features of hemorrhage from brain arteriovenous malformations. Stroke. 2009; 40(1):100-105. [PubMed: 19008469]

32. Marks M, Lane B, Steinberg G, Chang P. Hemorrhage in intracerebral arteriovenous malformations: angiographic determinants. Radiology. 1990; 176(3):807-813. [PubMed: 2389040]

33. Loeffler JS, Niemierko A, Chapman PH. Second tumors after radiosurgery: tip of the iceberg or a bump in the road? Neurosurgery. 2003; 52(6):1436-1442. [PubMed: 12762888]

34. Flickinger JC, Pollock BE, Kondziolka D, Lunsford LD. A dose-response analysis of arteriovenous malformation obliteration after radiosurgery. International Journal of Radiation Oncology* Biology* Physics. 1996; 36(4):873-879.

35. Flickinger JC, Kondziolka D, Maitz AH, Dade Lunsford L. An analysis of the dose-response for arteriovenous malformation radiosurgery and other factors affecting obliteration. Radiotherapy and oncology. 2002; 63(3):347-354. [PubMed: 12142099] 
36. Maruyama K, Kawahara N, Shin M, et al. The risk of hemorrhage after radiosurgery for cerebral arteriovenous malformations. New England Journal of Medicine. 2005; 352(2):146-153. [PubMed: 15647577]

37. Hattangadi JA, Chapman PH, Bussière MR, et al. Planned two-fraction proton beam stereotactic radiosurgery for high-risk inoperable cerebral arteriovenous malformations. International Journal of Radiation Oncology* Biology* Physics. 2012; 83(2):533-541.

38. Suit H, Goldberg S, Niemierko A, et al. Proton beams to replace photon beams in radical dose treatments. Acta Oncologica. 2003; 42(8):800-808. [PubMed: 14968940]

39. Miralbell R, Lomax A, Cella L, Schneider U. Potential reduction of the incidence of radiationinduced second cancers by using proton beams in the treatment of pediatric tumors. International Journal of Radiation Oncology* Biology* Physics. 2002; 54(3):824-829.

40. St Clair W, Adams J, Bues M, et al. Advantage of protons compared to conventional X-ray or IMRT in the treatment of a pediatric patient with medulloblastoma. International Journal of Radiation Oncology* Biology* Physics. 2004; 58(3):727-734.

41. Suit H, Kooy H, Trofimov A, et al. Should positive phase III clinical trial data be required before proton beam therapy is more widely adopted? No. Radiotherapy and Oncology. 2008; 86(2):148153. [PubMed: 18237800]

42. Loeffler JS, Durante M. Charged particle therapy—optimization, challenges and future directions. Nature Reviews Clinical Oncology. 2013

43. Potts MB, Young WL, Lawton MT. Deep Arteriovenous Malformations In the Basal Ganglia, Thalamus, and Insula: Microsurgical Management, Techniques, and Results. Neurosurgery. 2013

44. Han PP, Ponce FA, Spetzler RF. Intention-to-treat analysis of Spetzler-Martin grades IV and V arteriovenous malformations: natural history and treatment paradigm. Journal of neurosurgery. 2003; 98(1):3-7. [PubMed: 12546345]

45. O'Connor TE, Friedman WA. Magnetic Resonance Imaging Assessment of Cerebral Arteriovenous Malformation Obliteration After Stereotactic Radiosurgery. Neurosurgery. 2013

46. Pollock BE, Kondziolka D, Flickinger JC, Patel AK, Bissonette DJ, Lunsford LD. Magnetic resonance imaging: an accurate method to evaluate arteriovenous malformations after stereotactic radiosurgery. Journal of neurosurgery. 1996; 85(6):1044-1049. [PubMed: 8929493] 


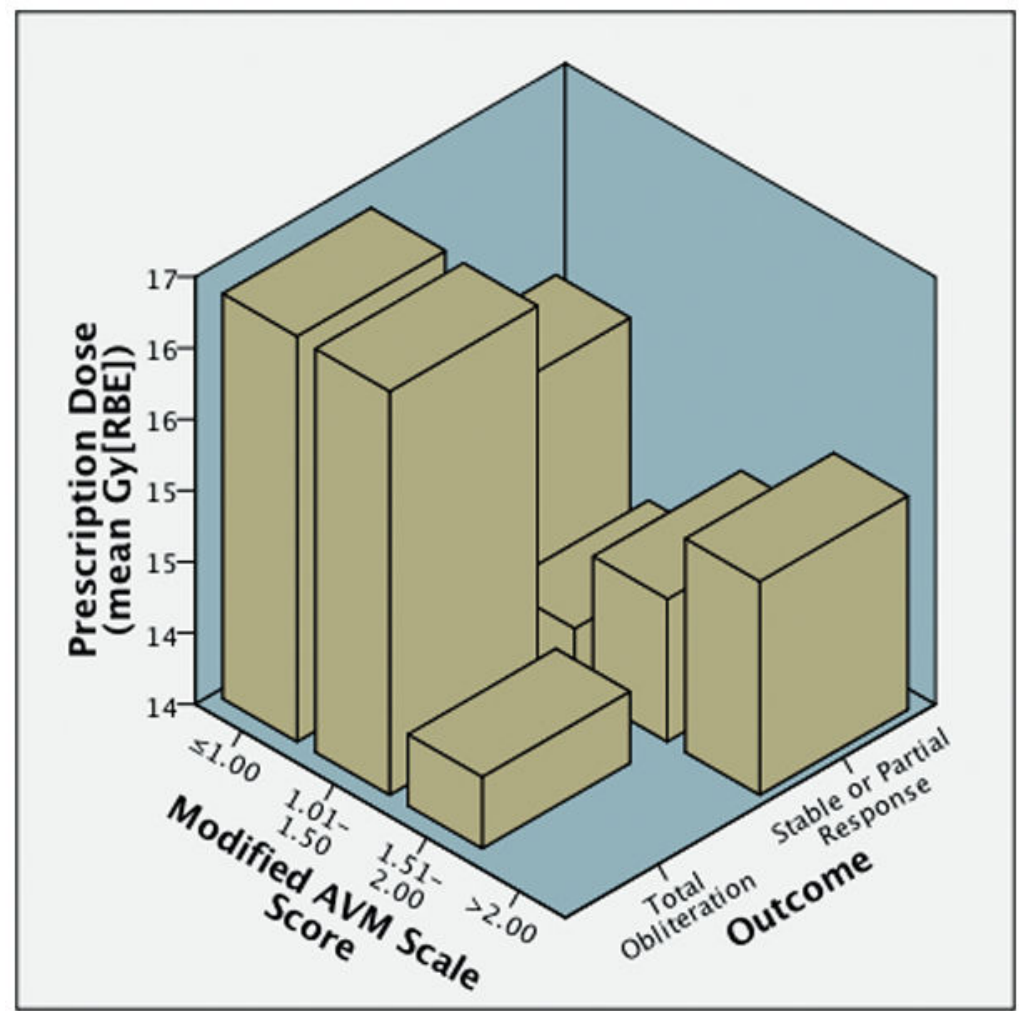

Figure 1.

Prescription dose and modified AVM scale score contribute to AVM obliteration rates. Both prescription dose and modified AVM scale score are associated with total AVM obliteration rates ( $p=0.01$ and 0.045 , respectively). The majority of AVMs that responded with total obliteration were treated with higher prescription doses and had smaller modified AVM scale scores. 


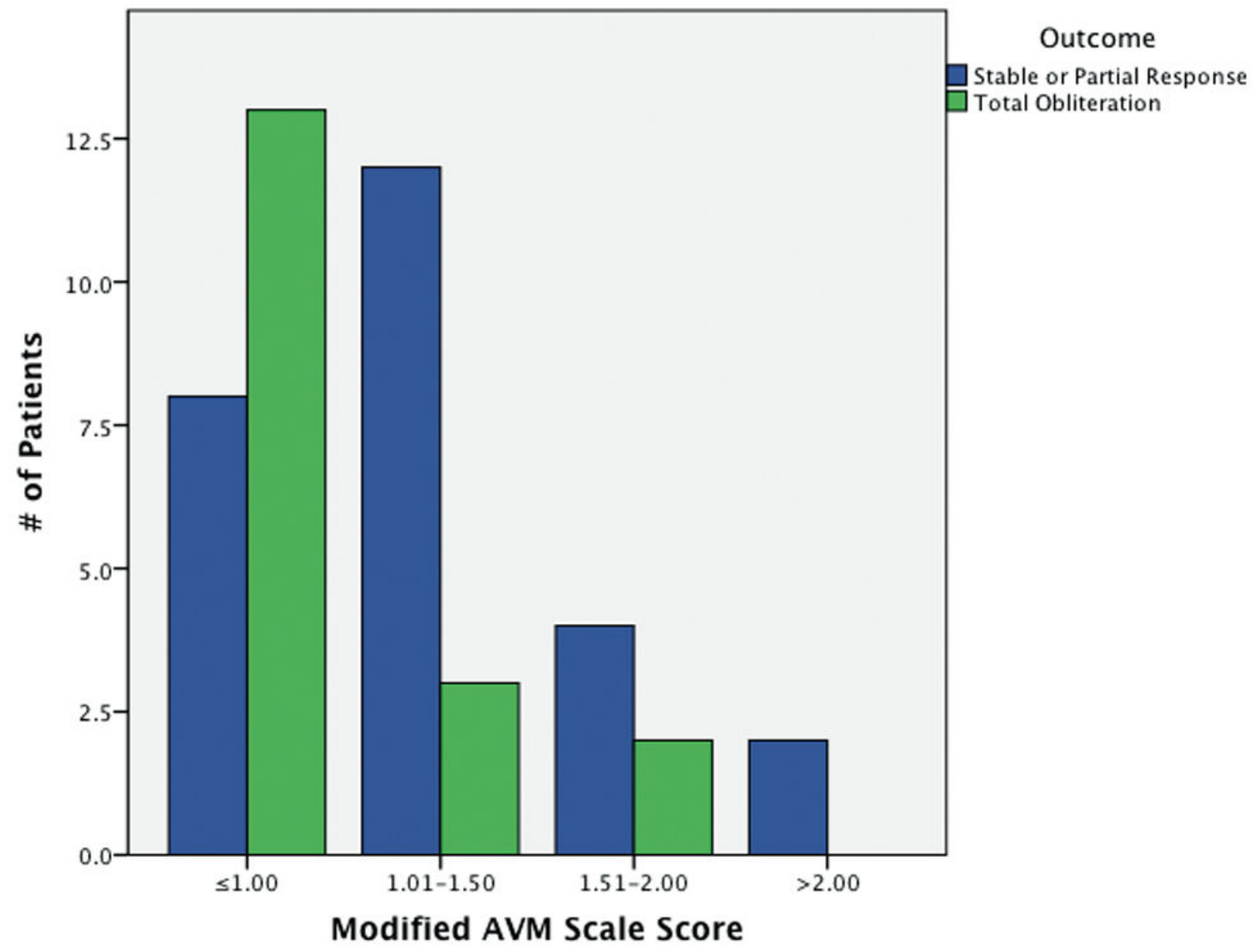

Figure 2.

Response rates to proton beam radiosurgery vary by modified AVM scale score. In a univariate analysis, modified AVM scale score was associated with total AVM obliteration rates in pediatric patients (Pearson $\chi^{2}, \mathrm{p}=0.045$ ). 


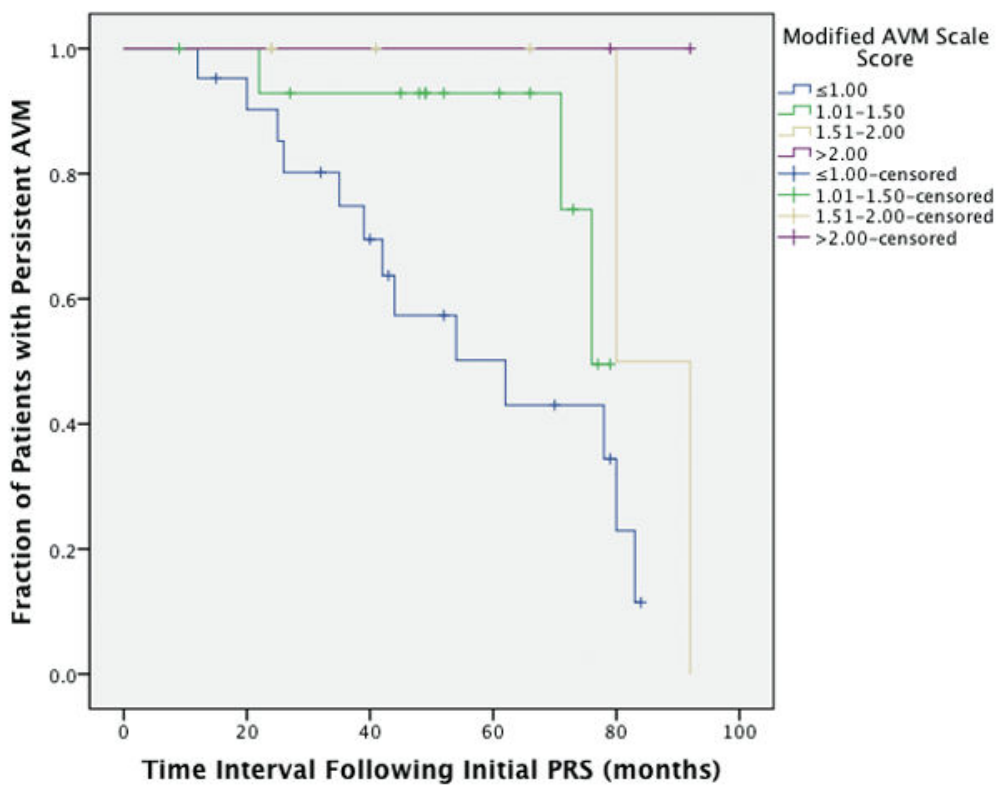

Figure 3.

Kaplan Meier estimator plots for total AVM obliteration. Estimated time to total AVM obliteration was plotted for each of the four different groups according to modified AVM scale score distribution ( $\leq 1.00,1.01-1.50,1.51-2.00,>2.00$ ). There was a significant difference in the test of equality for total obliteration distributions (Log Rank [Mantel$\operatorname{Cox}] \chi^{2}=8.26 ; p=0.04$ ). 


\section{Table 1}

\section{Modified AVM scale score calculation}

\begin{tabular}{|l|l|}
\hline Size + & $(0.1)($ volume, $\mathrm{mL})$ \\
\hline Age + & $(0.02)($ age, years $)$ \\
\hline Location + & $(0.3)$ (location, hemispheric/corpus callosum/cerebellar $=0 ;$ basal ganglia/thalamus/brainstem $=1)$ \\
\hline = Total score & \\
\hline
\end{tabular}


Table 2

Patient characteristics ${ }^{a}$

\begin{tabular}{|l|l|}
\hline Age, median (range in years) & $12(3-17)$ \\
\hline Sex & \\
\hline Male & $21(47.7)$ \\
\hline Female & $23(52.3)$ \\
\hline Presenting symptom & \\
\hline Headache & $3(6.8)$ \\
\hline AVM hemorrhage & $24(54.5)$ \\
\hline AVM-related aneurysm hemorrhage & $1(2.3)$ \\
\hline Seizure & $6(13.6)$ \\
\hline Incidental & $9(20.5)$ \\
\hline Unknown & $1(2.3)$ \\
\hline Prior treatments & \\
\hline Embolization & $7(15.9)$ \\
\hline Stereotactic radiosurgery, photon & $1(2.3)$ \\
\hline Surgery & $0(0)$ \\
\hline Modified AVM scale score, median \pm SD (range) & $1.1 \pm 0.6(0.2-3.2)$ \\
\hline$\leq 1.00$ & $21(47.7 \%)$ \\
\hline $1.01-1.50$ & $15(34.1 \%)$ \\
\hline $1.51-2.00$ & $6(13.6 \%)$ \\
\hline$>2.00$ & $2(4.5 \%)$ \\
\hline
\end{tabular}

${ }^{a}$ Data are presented as No. (\%) unless otherwise specified.

$\mathrm{SD}=$ standard deviation

$\mathrm{AVM}=$ arteriovenous malformation 
Table 3

Lesion \& treatment characteristics

\begin{tabular}{|l|l|}
\hline \# Fractions & \\
\hline One & $35(79.5)$ \\
\hline Two & $9(20.5)$ \\
\hline Second treatment (re-treatment) & $17(38.6)$ \\
\hline Treatment volume in mL, median \pm SD (range) & $6.2 \pm 4.9(0.3-18.1)$ \\
\hline Target volume in mL, median \pm SD (range) & $4.5 \pm 5.9(0.3-29.0)$ \\
\hline Location & \\
\hline Occipital lobe & $2(4.5)$ \\
\hline Thalamus & $20(45.5)$ \\
\hline Frontal & $10(22.7)$ \\
\hline Corpus callosum & $3(6.8)$ \\
\hline Brainstem & $2(4.5)$ \\
\hline Parietal lobe & $2(4.5)$ \\
\hline Cerebellum & $1(2.3)$ \\
\hline Temporal lobe & $2(4.5)$ \\
\hline Basal ganglia & $2(4.5)$ \\
\hline Median prescription dose in Gy[RBE] $\pm \mathrm{SD}($ range $)$ & $15.50 \pm 1.87(12-20)$ \\
\hline Median maximum dose (median) in Gy[RBE] $\pm \mathrm{SD}($ range $)$ & $17.01 \pm 2.19(13.34-22.20)$ \\
\hline Median minimum dose (median) in Gy[RBE] $\pm \mathrm{SD}($ range) & $14.10 \pm 2.59(7.68-20.00)$ \\
\hline Median homogeneity index $\pm \mathrm{SD}($ range $)$ & $1.12 \pm 0.06(0.88-1.33)$ \\
\hline Median maximum AVM diameter in cm $\pm \mathrm{SD}($ range $)$ & $3.6 \pm 1.5(1-6)$ \\
\hline
\end{tabular}

$\mathrm{Gy}[\mathrm{RBE}]=$ Gray radiobiologic equivalent

$\mathrm{SD}=$ standard deviation

$\mathrm{AVM}=$ arteriovenous malformation 


\section{Table 4}

\section{Treatment outcomes}

\begin{tabular}{|l|l|}
\hline Median follow-up, in months \pm SD (range) & $52 \pm 25(9-111)$ \\
\hline Overall obliteration rates & \\
\hline No response & $2(4.5)$ \\
\hline Partial obliteration & $24(59.1)$ \\
\hline Total obliteration & $18(40.9)$ \\
\hline Median time to obliteration in months \pm SD (range) & $49 \pm 26(12-92)$ \\
\hline Total AVM obliteration of patients undergoing re-treatment & $4(23.5 \%)$ \\
\hline Median time to hemorrhage in months \pm SD (range) & $45 \pm 15(30-66)$ \\
\hline Acute complications & \\
\hline Seizure & $1(2.3)$ \\
\hline None & $43(97.7)$ \\
\hline Late complications & \\
\hline Grade 1 headache & $1(2.3)$ \\
\hline Hemibody pain syndrome & $1(2.3)$ \\
\hline AVM hemorrhage following PSRS & $4(9.1)$ \\
\hline None & $38(86.4)$ \\
\hline
\end{tabular}

PSRS $=$ proton beam stereotactic radiosurgery

$\mathrm{SD}=$ standard deviation

$\mathrm{AVM}=$ arteriovenous malformation 


\section{Table 5}

Patient and treatment characteristics for 17 patients who required subsequent radiosurgery treatment (retreatment)

\begin{tabular}{|c|c|}
\hline Age, median (range in years) & $12(6-16)$ \\
\hline Interval to retreatment, mean $\pm \mathrm{SEM}$ (range in years) & $4.6 \pm 0.1(4-5)$ \\
\hline Modified AVM scale score, median \pm SD (range) & $1.1 \pm 0.8(0.2-3.2)$ \\
\hline$\unlhd .00$ & $7(41.2)$ \\
\hline $1.01-1.50$ & $5(29.4)$ \\
\hline $1.51-2.00$ & $3(17.6)$ \\
\hline$>2.00$ & $2(11.8)$ \\
\hline \multicolumn{2}{|l|}{ \# Fractions } \\
\hline One & 11 \\
\hline Two & 6 \\
\hline Treatment volume in $\mathrm{mL}$, median $\pm \mathrm{SD}$ (range) & $7.3 \pm 5.5(0.3-16.5)$ \\
\hline Target volume in $\mathrm{mL}$, median $\pm \mathrm{SD}$ (range) & $5.2 \pm 8.1(0.3-29)$ \\
\hline Median prescription dose in Gy[RBE] $\pm \mathrm{SD}$ (range) & $15.00 \pm 1.54(12-16)$ \\
\hline Median maximum dose (median) in Gy $[\mathrm{RBE}] \pm \mathrm{SD}$ (range) & $15.61 \pm 1.67(13.49-17.80)$ \\
\hline Median minimum dose (median) in Gy[RBE] $\pm \mathrm{SD}$ (range) & $13.45 \pm 3.00(7.68-16.04)$ \\
\hline Median homogeneity index \pm SD (range) & $1.12 \pm 0.07(0.88-1.13)$ \\
\hline Median maximum AVM diameter in $\mathrm{cm} \pm \mathrm{SD}$ (range) & $3.85 \pm 1.42(1-5)$ \\
\hline
\end{tabular}

Gy $[\mathrm{RBE}]=$ Gray radiobiologic equivalent

$\mathrm{SD}=$ standard deviation

$\mathrm{SEM}=$ standard error of mean

$\mathrm{AVM}=$ arteriovenous malformation 


\section{Table 6}

Association of variables related to total AVM obliteration

\begin{tabular}{|l|l|l|}
\hline Variable & Statistical Test & p value \\
\hline Age & Mann-Whitney U Test & 0.78 \\
\hline Maximum AVM diameter & Mann-Whitney U Test & 0.18 \\
\hline Target volume (smaller) & Mann-Whitney U Test & 0.03 \\
\hline Treatment volume (smaller) & Mann-Whitney U Test & 0.07 \\
\hline Prescription dose (larger) & Mann-Whitney U Test & 0.01 \\
\hline Maximum dose (larger) & Mann-Whitney U Test & $<0.001$ \\
\hline Minimum dose (larger) & Mann-Whitney U Test & 0.003 \\
\hline Homogeneity index & Mann-Whitney U Test & 0.85 \\
\hline Sex & Pearson $\chi^{2}$ & 0.80 \\
\hline \# of fractions (one) & Pearson $\chi^{2}$ & 0.04 \\
\hline Presentation with hemorrhage & Pearson $\chi^{2}$ & 0.63 \\
\hline History of embolization & Pearson $\chi^{2}$ & 0.07 \\
\hline Location & Pearson $\chi^{2}$ & 0.18 \\
\hline Modified AVM scale score & Pearson $\chi^{2}$ & 0.045 \\
\hline
\end{tabular}

